\title{
System Analysis and Design for Radio Frequency Identification (RFID) based Hospital Pharmacy Management and Monitoring System: A Case Study of Tanzania Public Hospitals
}

\author{
Prisila Ishabakaki \\ Department of Communication Science and \\ Engineering \\ Nelson Mandela AIST \\ Arusha, Tanzania
}

\author{
Shubi Kaijage \\ Department of Communication Science and \\ Engineering \\ Nelson Mandela AIST \\ Arusha, Tanzania
}

\begin{abstract}
System analysis and Design (SAD) are important steps in system development life cycle where it concerns with the techniques and approaches to develop systems more effectively and efficiently. SAD basically enables a system developer to analyze business processes more efficient and effective by considering real business environments and functions. The requirements are gathered and modeled to ensure the right approach in problem solving. In this paper the system analysis and design for the RFID based hospital pharmacy management and monitoring system the case of Tanzania public hospital is presented. The system aim at counteracting the public hospital pharmacy challenges which includes the manual processing of pharmacy activities, drug diversion and theft. The paper presents the methodologies employed to gather the system requirements, modeling of the requirement using UML and system design.
\end{abstract}

\section{General Terms}

System analysis and design

\section{Keywords}

System Analysis, system design, Radio Frequency Identification, RFID, pharmacy management and monitoring system.

\section{INTRODUCTION}

Radio Frequency identification (RFID) is a wireless based technology for identification of objects. The technology is now generating significant interest in the marketplace because of its robust application capabilities [1]. RFID utilizes electromagnetic waves for transmitting and receiving information stored in a tag to or from a reader [2]. RFID Technology has an edge over other identification systems such as barcode systems, magnetic strip cards, smart cards, and biometrics because it requires no line of sight for communication, sustains harsh physical environments, allows for simultaneous identification, has excellent data storage, wide read range and is cost and power efficient.

RFID can contribute in improving hospital operations by improving patient care and safety, optimizing the workflows, reducing the operating costs, and reducing costly thefts. Drug theft and diversion has been major problems to most public hospitals in developing countries [3, 4]. Resulting into serious effects to hospital stakeholders such that unavailability of drugs in hospitals, which can affect patient health, hospital loses money in replacing the loss and the government undergoes loss in fighting this problem. These challenges had stimulated researchers to find how the RFID technology can help to counteract the challenges. Apart from counteracting theft and diversion of the drugs also by implementing RFID in a hospital environment can as well benefit in reducing outof-stocks, reducing the time staff spends searching for medicine, optimizing the utilization of current stock especially near expiring items and identification of drugs to be ordered. This study present system analysis and design for the RFID based drug management and monitoring system in (RHPMMS) hospital environment with UML.

The Unified Modeling Language (UML) is a graphical modeling language mainly used for specifying, constructing and documenting aspects of object-oriented software [5]. UML has the advantage of being a powerful and flexible language in system analysis due consistent notation and integration capacity of diagramming techniques.

System development life cycle (SDLC) defines four development phases through which the complete system is developed, these includes planning, analysis, design and implementation [6]. System planning is the process of understanding why an information system is required and determining how to go about building the system. System analysis basically is essential in determining who is going to use the system, what will the system do (system requirements) and when it will be used. The analysis phase also includes the analysis of current system (manual system or information system) and requirement gathering through various gathering techniques [7]. The requirements are the descriptions of the services provided by the system and its operational constraints. The requirement engineering process is often called business process modeling which is very essential in developing an enterprise information system [8]. The requirement specification must comply to the characteristics, such as complete, consistent, correct, modifiable, ranked, traceable, unambiguous and verifiable [9].

Design phase of the SDLC involves determining how the system will operate, in terms of the hardware, software, network infrastructure, the user interface, forms, reports, databases, and files that will be needed. This step explains 
exactly how the system operates. The paper is organized as, firstly the methodologies used for gathering requirement as part of the analysis phase are described, and the requirements are presented on section II. Section III presents the requirement modeling with UML, section IV describes system design and section $\mathrm{V}$ concludes the paper.

\section{REQUIREMENT GATHERING METHODOLOGIES}

The requirement gathering was conducted at in Dar es Salaam and Arusha where by four public hospitals were visited. Various data collection method was used to capture system requirements these included observation, interview as well as written documentation reviews. The techniques employed are further explained below.

\subsection{Domain analysis}

Domain analysis is a process which involves understanding the background needed so as to be able to elicit the problem and make intelligent decisions [10]. The term domain means the general field of business or technology in which the customers expect to be using the software. The software developer has to understand the domain in which the system is thought to be implemented. The domain analysis in this study was conducted in two public hospitals in each region Dar es Salaam and Arusha Tanzania. Through interviewing with domain experts and observation a researcher was able to analyze the domain. It was identified that these hospital has no any system in place to assist the process. The pharmacy supply chain in hospitals start by the pharmacist preparing the order and submit to management for authorization. The hospital receives drugs in bulk quantity, the pharmacists in store, distribute to other hospital units. The process of tracking if the distributed drugs reach intended patients is difficult, rarely carried out by management paper based records pose challenges. Sometimes the staff doesn't update the record, especially during rush hours. It was identified that to fully monitor and manage the drug at public hospital settings there must be an end to end information system implementation that is from pharmacy store to each hospital unit. However, due to time constraints, this work is limited only to pharmacy store. Throughout this paper the requirement gathered and analyzed is for hospital pharmacy store management and monitoring.

\subsection{Feasibility study}

Involves information assessment, information collection and report writing. The information assessment identifies whether the system contributes to the overall objectives of the organization, cost effectiveness of the system and whether the expected system could be integrated with the existing system. The feasibility study was conducted in three public hospitals in Dar Es Salaam and Arusha regions, the hospitals had no system in place that serve the purpose despite the fact that the challenges persists. The use of RFID Technology in addressing the problems is very promising as through literature the technology has been reported being efficient in providing advantages like cost reduction by maintaining stock levels, reducing the out-of-stocks, counterfeit protection, shrinkage protection, and real-time tracking of supplies [11][12].

\subsection{Interview}

The requirements elicitation from the hospital in this study was achieved by conducting open interviews at hospitals. The main stakeholder involved in this interview was Medical in charge, IT personnel and pharmacists in each hospital visited. The researcher gathered information on how the process is conducted in which the system goal could be identified. Requirements can be gathered by means of open interviews. A more efficient way to gather requirements is to conduct less open interviews by reusing requirements patterns. These patterns can be used on new cases to guide the identification of requirements.

\subsection{Observation}

Observation means taking a note and shadowing important potential users as they do their work, writing down everything they do [13]. It is a technique in requirement gathering where a developer get the information that could be forgotten or ignored during interview or any other technique. The researcher used this technique to observer the process at pharmacy store and was able to identify that the process of retrieving information about the disbursement of the drugs say for last three month is very difficult it require one to go through several books to obtain the required information and this could be the loophole for diversion since one knows how difficult is to track the process.

\section{SYSTEM REQUIREMENTS}

Functional and non-functional system requirement were identified as presented in Table 1 and 2 respectively

\subsection{Functional Requirements}

Table 1: System Functional Requirements

\begin{tabular}{|c|c|}
\hline Requirements & Description \\
\hline $\begin{array}{l}\text { Authenticating } \\
\text { users }\end{array}$ & $\begin{array}{l}\text { The system must allow only authorized } \\
\text { users to login and interact with the system. } \\
\text { The system administrator the IT personnel } \\
\text { will be responsible to create users and } \\
\text { password and share it, users can edit the } \\
\text { password after logging into the system. }\end{array}$ \\
\hline $\begin{array}{l}\text { Receive and } \\
\text { distribute drugs }\end{array}$ & $\begin{array}{l}\text { Receive and distribute drug supplies in all } \\
\text { hospital settings (such as wards, outpatients, } \\
\text { emergency, etc.) These hospital settings are } \\
\text { regarded as customers to pharmacy store. }\end{array}$ \\
\hline $\begin{array}{l}\text { Creating a drug } \\
\text { profile }\end{array}$ & $\begin{array}{l}\text { Each drug has its own profile, the system } \\
\text { will allow the pharmacist to create, update } \\
\text { or delete drug profiles. }\end{array}$ \\
\hline $\begin{array}{l}\text { Stock ordering } \\
\text { and approval }\end{array}$ & $\begin{array}{l}\text { The pharmacist creates new order } \\
\text { requirement expected purchase list } \\
\text { depending on stock levels and submit the } \\
\text { order to medical in charge for approval. } \\
\text { The medical in charge has to approve the } \\
\text { prepared list before it is sent to the supplier. }\end{array}$ \\
\hline $\begin{array}{l}\text { Notification on } \\
\text { stock status }\end{array}$ & $\begin{array}{l}\text { The system has to display alerts to } \\
\text { pharmacists and management personnel up } \\
\text { on nearly expiring items this has to be done } \\
\text { two weeks before expiring the alerts will be } \\
\text { activated. } \\
\text { The system also has to alerts the pharmacist } \\
\text { and management upon reorder level. }\end{array}$ \\
\hline $\begin{array}{l}\text { Interfacing with } \\
\text { RFID Reader }\end{array}$ & $\begin{array}{l}\text { For the purpose of drug monitoring the } \\
\text { system will be interfaced with RFID } \\
\text { Reader, the system should receive the } \\
\text { information gathered from reader initiate } \\
\text { communication, process and store } \\
\text { information read by readers and trigger the } \\
\text { alarm and alert the authority upon } \\
\text { unauthorized detection transaction. }\end{array}$ \\
\hline
\end{tabular}




\begin{tabular}{|l|l|}
\hline $\begin{array}{l}\text { Summaries and } \\
\text { report }\end{array}$ & $\begin{array}{l}\text { The system should allow the management } \\
\text { and audit team to track all system } \\
\text { transactions by providing a summary and } \\
\text { report on all transactions in a specified } \\
\text { period. }\end{array}$ \\
\hline $\begin{array}{l}\text { System } \\
\text { Administration }\end{array}$ & $\begin{array}{l}\text { The system should allow the administrator } \\
\text { to monitor system activities such as } \\
\text { registering new users, remove or update } \\
\text { user details. }\end{array}$ \\
\hline $\begin{array}{l}\text { Customer } \\
\text { request } \\
\text { processing }\end{array}$ & $\begin{array}{l}\text { The pharmacy store is responsible in } \\
\text { distributing the drug across all hospital } \\
\text { settings (these will be regarded as a } \\
\text { customer into our system). The system } \\
\text { should allow customer to request the drugs. }\end{array}$ \\
\hline
\end{tabular}

\subsection{Nonfunctional requirements}

Table 2: Nonfunctional system requirements

\begin{tabular}{|c|c|}
\hline Requirement & Description \\
\hline Operability & $\begin{array}{l}\text { The system code shall be in web based } \\
\text { programming languages such as HTML and } \\
\text { PHP. It shall also be able to interconnect } \\
\text { with MySQL database and the selected RFID } \\
\text { reader. }\end{array}$ \\
\hline Availability & $\begin{array}{l}\text { The system shall be capable of being } \\
\text { available both online and local, depending on } \\
\text { the available infrastructure on the hospital }\end{array}$ \\
\hline $\begin{array}{l}\text { Maintainabi } \\
\text { lity }\end{array}$ & $\begin{array}{l}\text { The system shall be able to upgrade to } \\
\text { connect with external supplier systems such } \\
\text { as MSD to offer fully automated drug } \\
\text { ordering and management system. The } \\
\text { system also should allow interconnection } \\
\text { with pharmacy dispensing units for more } \\
\text { efficient control process }\end{array}$ \\
\hline Secu & $\begin{array}{l}\text { The system shall provide access to only } \\
\text { registered users. The authorized users will be } \\
\text { given login credentials to login. The } \\
\text { algorithms for strong password will be } \\
\text { deployed to prevent brute force }\end{array}$ \\
\hline $\begin{array}{l}\text { Performanc } \\
\text { e }\end{array}$ & $\begin{array}{l}\text { The total response time for an RFID reader to } \\
\text { detect a tag, communicate with a system and } \\
\text { system response will keep short. }\end{array}$ \\
\hline $\begin{array}{l}\text { User } \\
\text { Interface }\end{array}$ & $\begin{array}{l}\text { Graphical User Interface (GUI) is generally } \\
\text { provides easy way use the system even for } \\
\text { non computer literacy. The system should } \\
\text { implement graphical user interface. }\end{array}$ \\
\hline
\end{tabular}

\section{SYSTEM REQUIREMENT} MODELING

This section present the system requirement models where the use case, data flow diagram and entity relation diagram are presented.

\subsection{Use case modeling}

Use case is the diagram that shows the relationships among actors and use cases within a system. Sommerville defined use case as scenario based technique for requirement elicitation and they are used for describing object oriented system models [14]. It actually provides an overview of all or part of the usage requirements for a system or organization in the form of an essential model or a business model, communicate the scope of system development and model analysis of usage system requirements. Requirements are described with system use case diagrams in UML approach. Business use case models facilitate the development of system use case models[15]. Four actors were identified for developing hospital pharmacy management and monitoring system. Figure 1 depicts interactions between the actors and the hospital pharmacy management and monitoring system. Since this system development is use-case driven means that use cases are the primary modeling tool to define the behavior of the system from the use case other models will be derived.

\subsubsection{Detailed use case}

Under this section the author has selected some use case to elaborate it in details.

Table 3 shows the details of the "Add drug profile" use case:

Table 3: Detailed "add drug profile" use case

\begin{tabular}{|l|r|}
\hline Use case & Add drug profile \\
\hline Actor & Pharmacist \\
\hline Pre request & $\begin{array}{l}\text { Pharmacist in charge has been registered } \\
\text { on the system } \\
\text { The pharmacist has login credentials }\end{array}$ \\
\hline Flow of events & $\begin{array}{r}\text { Pharmacist in charge provides } \\
\text { login credentials }\end{array}$ \\
2. & $\begin{array}{l}\text { Pharmacist in charge select the } \\
\text { add drug profile link } \\
\text { An interface for adding drug } \\
\text { profile is provided be the system } \\
\text { The drug information is filled, } \\
\text { and submitted to the system } \\
\text { The update information stored in } \\
\text { the database }\end{array}$ \\
\hline Exceptions & $\begin{array}{l}\text { Invalid data type inputs } \\
\text { Entering the details that already } \\
\text { exist }\end{array}$ \\
\hline Post-condition & $\begin{array}{l}\text { The entered information is stored } \\
\text { into the system. }\end{array}$ \\
\hline
\end{tabular}




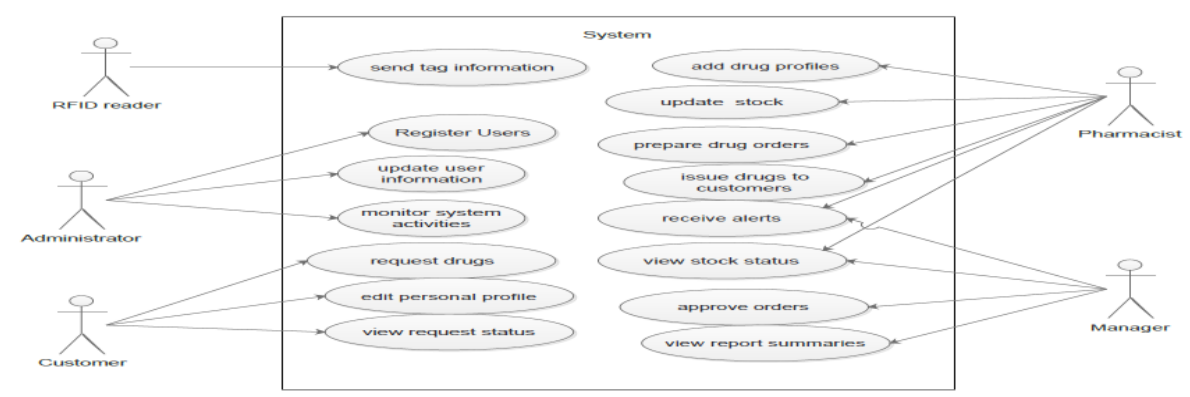

Figure 1: System use case

Table 4 details the Use case "Register user"

Table 4: "register user" use case

\begin{tabular}{|l|l|}
\hline Use case & \multicolumn{1}{|l|}{ Register new user } \\
\hline Actor & Administrator \\
\hline Pre-condition & $\begin{array}{l}\text { - } \\
\text { The administrator has been given admin } \\
\text { privilege in the system } \\
\text { User to be registered must be a health } \\
\text { worker at a given hospital either a } \\
\text { pharmacist, hospital units staff or } \\
\text { management audit time }\end{array}$ \\
\hline Flow of events & $\begin{array}{l}\text { 1. } \\
\text { Administrator login by providing his/her } \\
\text { credentials } \\
\text { Administrator fills the user details and } \\
\text { submit to the system } \\
\text { The system validates details and stores } \\
\text { the entries. }\end{array}$ \\
\hline Exceptions & $\begin{array}{l}\text { Repeating user information } \\
\text { Some information is missing }\end{array}$ \\
\hline Post-condition & \begin{tabular}{l} 
Entries are saved into the system \\
\hline
\end{tabular} \\
\hline
\end{tabular}

Table 5 details the "update stock" use case where by the actor is pharmacist.

Table 5: "Update stock" use case

\begin{tabular}{|c|c|}
\hline Use case & Update stock \\
\hline Actor & Pharmacist \\
\hline Pre-condition & $\begin{array}{l}\text { - The pharmacist has been } \\
\text { registered in the system } \\
\text { - The pharmacist has login } \\
\text { credentials } \\
\text { The hospital has received new } \\
\text { drug stock. }\end{array}$ \\
\hline Flow of events & $\begin{array}{l}\text { 1. Pharmacist login } \\
\text { 2. Pharmacist select update stock } \\
\text { from system menu. } \\
\text { 3. Add item and scan its RFID tag } \\
\text { 4. The entries are updated into the } \\
\text { system }\end{array}$ \\
\hline
\end{tabular}

\begin{tabular}{|c|c|}
\hline Exceptions & $\begin{array}{ll}\text { - } & \text { Missing information } \\
\text { - } & \text { Tag_id in use by other item }\end{array}$ \\
\hline Post-c & updated into the system. \\
\hline
\end{tabular}

\subsection{Data Flow Model}

The data flow model as an intuitive way of showing how data is processed by a system [14]. The data flow model is used to show how data flows through a sequence of processing steps. DFDs also model holding tanks (data stores), and external entities, which represent interfaces with objects outside the bounds of the system being modeled [8]. The advantage of a DFD is that it can describe information flows clearly, from the source to the destination. The common representation of the data flow model is the UML data flow diagrams. Data flow diagram (DFD) is a graphical tool that allows analysts to depict the flow of data in an information system. DFDs help system designers and stakeholders during initial analysis stages visualize a current system or one that may be necessary to meet new requirements. The DFD in this study is used to show how data flow within the system. The context diagram explains the system within the context of its environment. It also shows the boundaries, external environment and major information flow into the system. The general system process labeled 0 represents the entire system. The main system process is further narrowed down the; eight sub processes are identified as presented in figure 3 .

\subsection{Conceptual data modeling}

A conceptual data model (CDM) provides a notation by which the structural properties of data (the structuring of data and their relationships) from a certain domain [16]. The data structures include data objects or often called data types, associations between data objects (the relationship), and rules which govern operations on the objects. The goal of database modeling is to design an efficient and appropriate database for intended system [17]. Performance, integrity, comprehensibility and expandability are the most important criteria in conceptual modeling. However, it was identified by researchers that the optimal database design is difficult to achieve requiring an in-depth and careful requirement analysis to determine how the different and conflicting informational needs of users can best be satisfied. The 


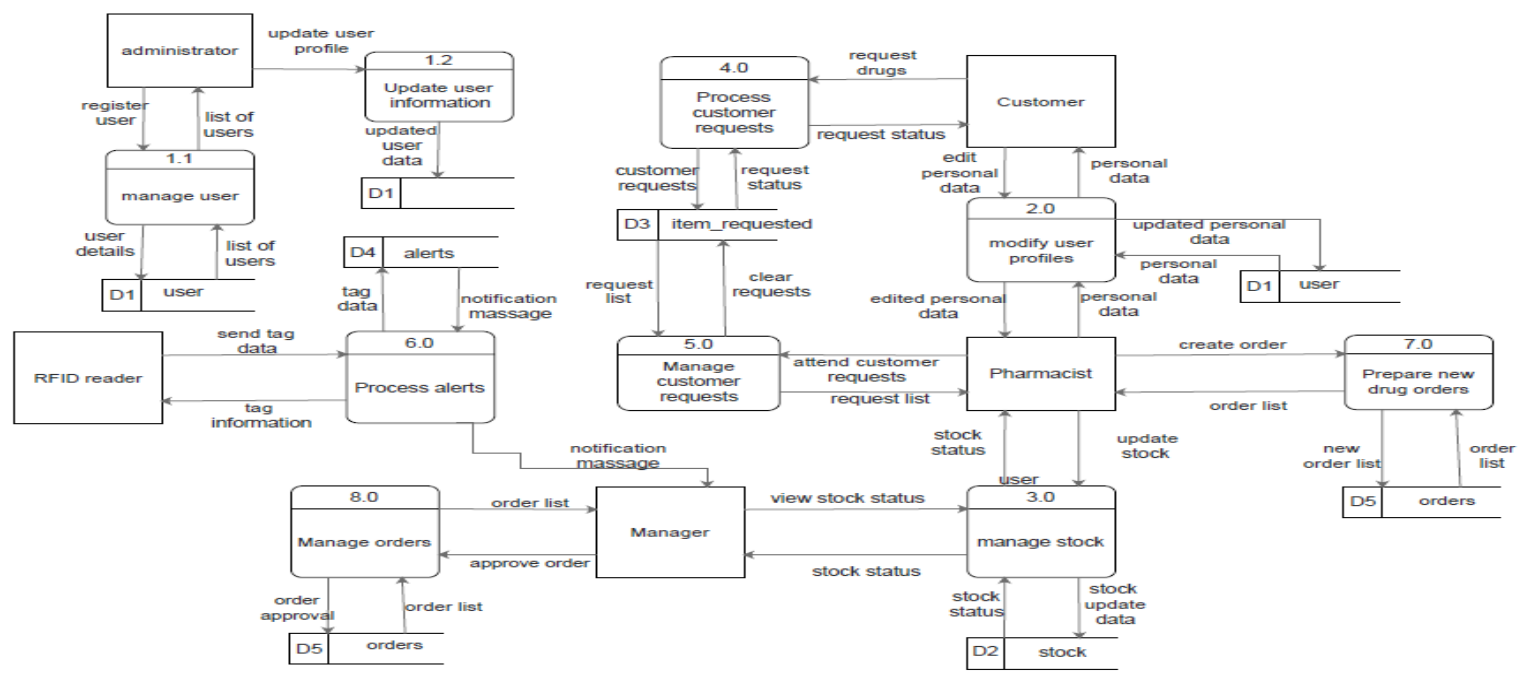

Figure 2: Level 0 DFD of RHPMMS

development of conceptual model has been careful derived from the user requirements described above and it has been the result of other requirement modeling such as data flow diagram and use case presented in previous subsections. The common output of the stage of system design is the entity relationship diagram (ERD). The most widely used conceptual model is an entity relation (ER) model and class diagram of the UML. In this paper, we present the entity relation diagram as shown in figure 4 .

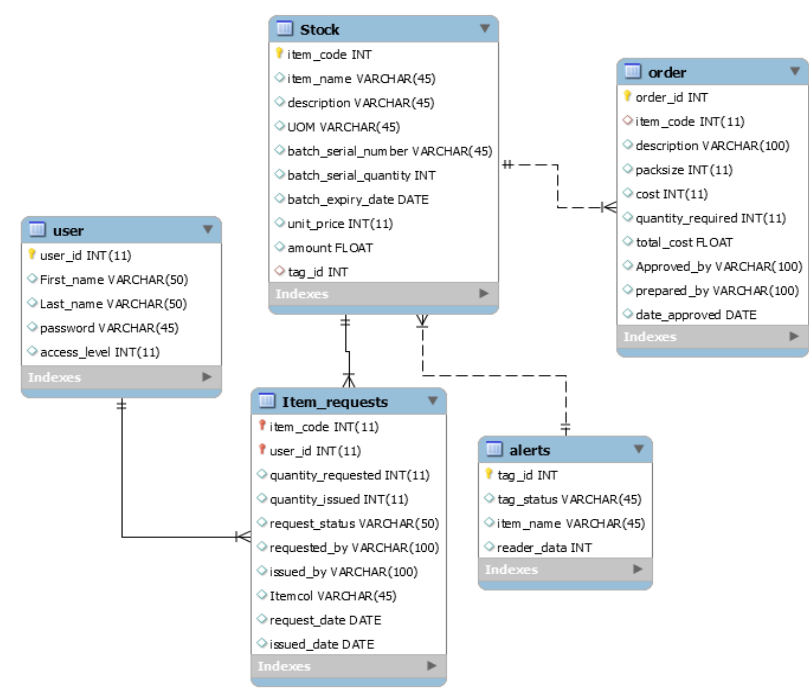

Figure 3: Entity Relation Diagram of RHPMMS

\section{SYSTEM DESIGN}

\subsection{User interface}

The user interface is the part of the system with which user interact to system. It involves the displays that provide navigation through the system, forms that capture data, and the reports that the system produces. Generally the system user interface design is made up of three components; navigation design, input design, and output design. The system user interface for RHPMMS is for all users are the web based interface designed with PHP. Figure 4 depicts the pharmacist use interface for creating drug profile into the system. PHP is the open source server side scripting language with high power in making dynamic and interactive Web pages. The advantages of PHP in web based software development are; independent of platform, open source, has high performance, flexibility and scalability; reliable and has security. Taking these advantages the system user interface was designed with PHP. User experience is a key criterion for designing user interfaces. Interfaces should be designed for both non experienced and experienced users. Novice users are concerned with ease of learning how quickly they can learn new systems. Expert users are most concerned with ease of use such that how quickly they can use the system. According to interviews done with expected system users they are nonexperienced and thus the interface design for each user incorporates menu which shows all available system functions as this promote ease of learning

\subsection{Data management}

The study adopts the database management system (DBMS) and structured query language (SQL) statement to provide the function of data retrieval and storage for users. It helps minimize the time used and human mistakes in preparing the 


\section{RHPMOM SYSTEN}

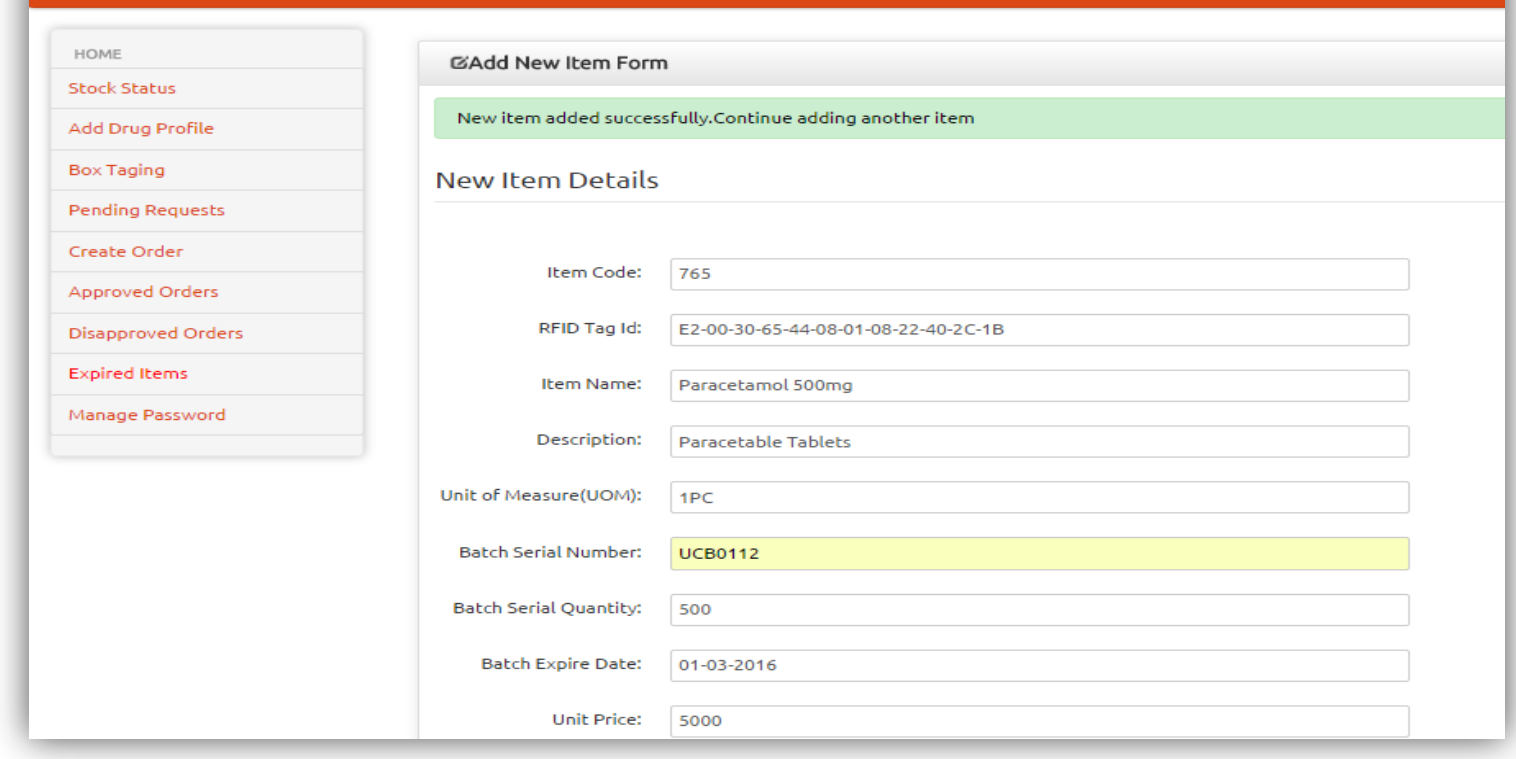

Figure 4: Issue drug interface

program statement for obtaining the required datasets are avoided. In order to increase the speed of data retrieval in the database, Query optimization technique is applied into RHPMMS. Figure 6 shows the general system architecture, the RFID network consisting of tags and reader is deployed to capture data, the data is stored in the central database, it is accessed by the processing module through query optimization techniques. The RFID middleware is a module for filtering and routing the data to the database. The software plays a vital role in removing duplicates, efficient use of network bandwidth as well as avoiding confusing information into the system [18].

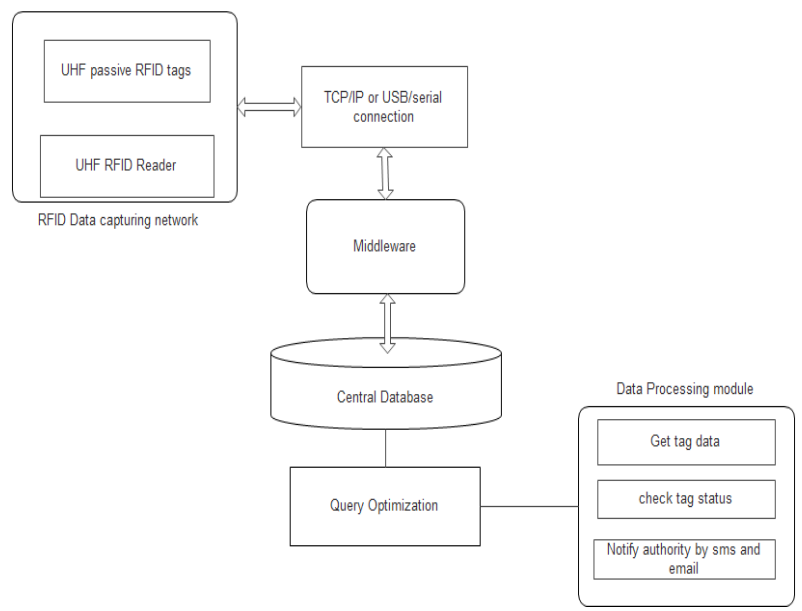

Figure 5: General System architecture

\section{CONCLUSION}

Deploying RFID technology in addressing health sector problem is promising due to the automated capability of this technology, therefore calling for less human involvement in operating the system. However, in any information system development one has to undergo the four basic phases of the System development life cycle (SDLC) which are planned, analysis, design and implementation. In this study, the system analysis and design phases are introduced. These phases are very significant processed in software development to ensure that the project resolves the right problem with a right approach. Failure in these stages will lead to project failure and can bring catastrophes in information system being developed. Results presented will be the basis for the implementation of hospital pharmacy management and monitoring system and integrated with RFID technology. As a consequence of this work system analysis and design, can be concluded that information system plays vital role in addressing health sector challenges, thus system developer must take care the initial design phases to ensure the intended design will fit user requirements and real environment considered. The future work will involve integration of the designed system with RFID network.

\section{ACKNOWLEDGMENTS}

Much thanks to the Nelson Mandela African Institution of science and technology for financing this research.

\section{REFERENCES}

[1] T. I. Cerlinca, C. Turcu, C. Turcu, and M. Cerlinca, "RFID-based Information System for Patients and Medical Staff Identification and Tracking," Sustain. Radio Freq. Identif. Solut., no. February, 2010.

[2] A. Rida, L. Yang, and M. Tentzeris, RFID-Enabled Sensor Design and applications. LONDON: British Library, 2010.

[3] The Guardian, "MSD launches drug labeling plan to curb drug theft," IPP Media, 12-Apr-2013. [Online]. Available: http://www.ippmedia.com/frontend/?1=53455.

[4] R. Bate, K. Hess, and L. Mooney, "Antimalarial medicine diversion: stock-outs and other public health problems," Res. Reports Trop. Med., pp. 19-24, 2010. 
[5] J. Rumbaugh, I. Jacobson, and G. Booch, Unified Modeling Language Reference Manual, The. Pearson Higher Education, 2004.

[6] A. Dennis, B. H. Wixom, and D. Tegarden, Systems Analysis \& Design, Second Edi. John Wiley \& Sons, Inc., 2005.

[7] D. Pandey, U. Suman, and A. K. Ramani, “An Effective Requirement Engineering Process Model for Software Development and Requirements Management," $A d v$. Recent Technol. Commun. Comput. (ARTCom), 2010 Int. Conf., 2010.

[8] H. Shen, B. Wall, M. Zaremba, Y. Chen, and J. Browne, "Integration of business modelling methods for enterprise information system analysis and user requirements gathering," Comput. Ind., vol. 54, no. 3, pp. 307-323, 2004.

[9] W. M. Wilson, L. H. Rosenberg, and L. E. Hyatt, "Automated analysis of requirement specifications," in Proceedings of the 19th international conference on Software engineering, 1997, pp. 161-171.

[10] T. C. Lethbridge and R. Laganière, Object-Oriented Software Engineering: Practical software development using UML and Java, Second. London: McGraw-Hill Education, 2005.

[11] Z. Hamid and R. Asher, "Counterfeit Drugs Prevention in Pharmaceutical Industry with RFID: A Framework
Based On Literature Review," Int. J. Medical, Heal. Biomed. Pharm. Eng., vol. 8, no. 4, pp. 198-206, 2014.

[12] A. M. Wicks, J. K. Visich, and S. Li, "Radio frequency identification applications in hospital environments," Hosp. Top., vol. 84, no. 3, pp. 3-9, 2006.

[13] K. Barclay and J. Savage, Object-Oriented Design with UML and Java, First. Amsterdam: Elsevier ButterworthHeinemann, 2004.

[14] I. Sommerville, software Engineering, 8th ed. Pearson Education Limited, 2007.

[15] I. Jacobson, G. Booch, and J. Rumbaugh, The unified software development process, vol. 1. Addison-Wesley Reading, 1999.

[16] N. W. Paton, E. Bornberg-bauer, and N. W. Paton, "Conceptual data modelling for bioinformatics," vol. 3, no. 2, pp. 166-180, 2002.

[17] B. Thalheim, Entity-relationship modeling: foundations of database technology. Springer Science \& Business Media, 2013.

[18] Y.-W. Ma, H.-C. Chao, J.-L. Chen, and C.-Y. Wu, "Load-balancing mechanism for the RFID middleware applications over grid networking," J. Netw. Comput. Appl., vol. 34, no. 3, pp. 811-820, 2011. 